\title{
Extended coverage of Gold Bulletin by Thomson Scientific...
}

Thomson Scientific inform us that from Volume 37 (1/2), 2004, they have extended their coverage of the contents of Gold Bulletin. As well as Science Citation Index (Expanded), also known as "SciSearch", and Materials Citation Index, they are now indexed in Science Citation Index and Current Contents/ Physical \& Earth Sciences.

\section{PUBLISHING IN GOLD BULLETIN: INFORMATION FOR AUTHORS}

Scope of journal: All aspects of the science, technology and applications of gold, encompassing chemistry, catalysis, materials, nanotechnology, biomedical and engineering practice, historical overviews $\&$ research, etc, and including characterisation, production, properties and applications.

\section{Types of contribution:}

- Papers: dealing with research and practice, typically 2,000 - 5,000 words plus figures and tables.

- Short Note: preliminary announcements of the results of topical research or accounts of limited investigations or of new techniques, typically 1,000 - 1,500 words plus up to 4 figures and/or tables.

- Critical review: should deal with their subject in broad perspective, examine the current position critically and comprehensively and look to future developments; typically 4,000 - 5,000 words plus figures and tables and well referenced.

- Conference reports: should be succinct and focused on topical aspects of gold in relation to conference theme and presentations, set in context.

Guidelines for authors: can be found on the journal's website, www.goldbulletin.org at: www.goldbulletin.org/content/view/11/30/ 